\title{
Article \\ Collaborative Assessment and Health Risk of Heavy Metals in Soils and Tea Leaves in the Southwest Region of China
}

\author{
Juan Liu ${ }^{1,2,+}$, Weihong Lu ${ }^{1,2,+}$, Naiming Zhang ${ }^{2,3, *}$, Dan Su ${ }^{2,3}$, Ladu Zeer ${ }^{2,3}$, Hongdie Du ${ }^{2,3}$ and Kelin Hu ${ }^{4}$ \\ 1 College of Plant Protection, Yunnan Agricultural University, Kunming 650201, China; \\ 15587214232@163.com (J.L.); luweihong_002@163.com (W.L.) \\ 2 Yunnan Soil Fertility and Pollution Restoration Laboratory, Yunnan Agricultural University, Kunming 650201, \\ China; Sd572018796@163.com (D.S.); ZELD196725@163.com (L.Z.); DuHongDieDHD@163.com (H.D.) \\ 3 College of Resource and Environment Science, Yunnan Agricultural University, Kunming 650201, China \\ 4 College of Resource and Environment Science, China Agricultural University, Beijing 100094, China; \\ hukel@cau.edu.cn \\ * Correspondence: zhangnaiming@ynau.edu.cn; Tel.: +86-871-65229840 \\ + Juan Liu and Weihong Lu as Co-first author.
}

Citation: Liu, J.; Lu, W.; Zhang, N.; $\mathrm{Su}, \mathrm{D}$.; Zeer, L.; Du, H.; Hu, K. Collaborative Assessment and Health Risk of Heavy Metals in Soils and Tea Leaves in the Southwest Region of China. Int. J. Environ. Res. Public Health 2021, 18, 10151. https:// doi.org/10.3390/ijerph181910151

Academic Editor: Paul B. Tchounwou

Received: 10 August 2021

Accepted: 20 September 2021

Published: 27 September 2021

Publisher's Note: MDPI stays neutral with regard to jurisdictional claims in published maps and institutional affiliations.

Copyright: (c) 2021 by the authors. Licensee MDPI, Basel, Switzerland. This article is an open access article distributed under the terms and conditions of the Creative Commons Attribution (CC BY) license (https:// creativecommons.org/licenses/by/ $4.0 /)$.

\begin{abstract}
The collaborative assessment and health risk evaluation of heavy metals (HMs) enrichment in soils and tea leaves are crucial to guarantee consumer safety. However, in high soil HM geochemical background areas superimposed by human activities, the health risk associated with HMs in soil-tea systems is not clear. This study assessed the HMs concentration (i.e., chromium (Cr), cadmium (Cd), arsenic (As), and lead $(\mathrm{Pb})$ ) in tea leaves and their relationship with soil amounts in the southwest region of China to evaluate the associated health risk in adults. The results revealed that the average soil concentration of $\mathrm{Cr}$ was the highest $\left(79.06 \mathrm{mg} \mathrm{kg}^{-1}\right)$, followed by $\mathrm{Pb}\left(29.27 \mathrm{mg} \mathrm{kg}^{-1}\right)$, As $\left(14.87 \mathrm{mg} \mathrm{kg}^{-1}\right)$, and $\mathrm{Cd}\left(0.18 \mathrm{mg} \mathrm{kg}^{-1}\right)$. Approximately $0.71,4.99,7.36$, and $10.21 \%$ of soil samples exceeded the threshold values (NY/T 853-2004) for $\mathrm{Pb}, \mathrm{Cr}$, As, and Cd, respectively. Furthermore, the average concentration of $\mathrm{Pb}, \mathrm{As}$, and $\mathrm{Cd}$ in tea leaves was below the corresponding residue limits, but $\mathrm{Cr}$ was above the allowed limits. Correlation analysis revealed that the $\mathrm{Pb}, \mathrm{Cr}$, $\mathrm{As}$, and $\mathrm{Cd}$ amounts in tea leaves were positively correlated to their soil amounts $(p<0.01)$ with an $R^{2}$ of 0.203 **, $0.074^{* *}, 0.036^{* *}$, and $0.090^{* *}$, respectively. Additionally, approximately $40.38 \%$ of the samples were found to be contaminated. Furthermore, spatial distribution statistical analysis revealed that Lancang was moderately contaminated, while Yingjiang, Zhenkang, Yongde, Zhenyuan, Lüchun, Jingdong, Ximeng, and Menglian were slightly contaminated areas. The target hazard quotients (THQ; health risk assessment) of $\mathrm{Pb}, \mathrm{Cr}, \mathrm{As}$, and $\mathrm{Cd}$ and the hazard index ( $\mathrm{HI}$ ) of all the counties were below unity, suggesting unlikely health risks from tea consumption.
\end{abstract}

Keywords: tea leaves; heavy metal; health risk; tea plantation soil; impact index of comprehensive quality

\section{Core ideas:}

- China has the largest tea plantation area and production in the world.

- Tea is unlikely to be a health risk to tea consumers.

- Heavy metals (HMs) enrichment in tea leaves is strongly linked to soil HMs amounts.

- Soil Cr was slightly above the normal level in the southwest region of China.

\section{Introduction}

Tea is among the three most popular non-alcoholic beverages worldwide [1]. It is mainly cultivated in Asia, Europe, East Africa, and South American countries, such as India, Kenya, China, Sri Lanka, and Turkey [1-3]. In 2019, world tea consumption was 5.859 million tons. Regular tea drinking is considered good for human health for beneficial tea components such as amino acids, tannins, polyphenols (catechins), and other antioxidants $[4,5]$. Furthermore, tea can supplement essential trace elements such 
as zinc, selenium, potassium, copper, boron, manganese, and strontium [6,7]. However, recently, there has been concern about heavy metals (HMs; arsenic (As), stibium ( $\mathrm{Sb}$ ), nickel $(\mathrm{Ni})$, copper $(\mathrm{Cu})$, thallium $(\mathrm{Tl})$, mercury $(\mathrm{Hg})$, cadmium $(\mathrm{Cd})$, and chromium $(\mathrm{Cr})$ ) contaminating tea leaves from soils, especially $\mathrm{Pb}$ and $\mathrm{Cd}$ contamination [8]. The toxicities of $\mathrm{HMs}$ such as $\mathrm{Cd}, \mathrm{Cr}, \mathrm{As}$, and $\mathrm{Pb}$ are recognized as major human risks worldwide [9]. Zhang et al. [10] reported $\mathrm{Cd}, \mathrm{Pb}$, and as pollution in tea plantation soil and $\mathrm{Pb}$ in tea leaves from Guizhou province, China; albeit, without serious risk to humans. Yaylalı-Abanuz et al. [11] reported $\mathrm{Cd}, \mathrm{Cu}$, and $\mathrm{Hg}$ contamination in the tea plantation soil of the mining area of eastern Black Sea in Turkey, with a relatively higher level of HMs in tea leaves compared to other countries.

Urbanization [12], mines [13], smelting [14], and agricultural activities [15] are the major anthropogenic pollution sources of HMs, whereas a high geochemical background can also naturally affect the soil HMs level [16]. Given the popularity and health benefits of tea, the risk assessment of HMs in tea plantation soil and leaves is crucial to ensure tea quality and safety [17]. However, the classic assessment methods, such as the single-factor index [18], potential ecological risk index [19], geo-accumulation [20], and Nemerow comprehensive index [21], have failed to integrate the HMs content in soil and agricultural products. Additionally, these ignore the problem of compound pollution, which often makes their assessment questionable. The comprehensive index method, which incorporates both soil and agricultural product contamination, can be a better approach for a close assessment of HMs pollution in farmland soil [22].

China has the largest tea plantation area and production in the world [10]. As the originator of tea trees, the southwest region of China had a tea planting area of $143.97 \times 10^{4} \mathrm{ha}^{-1}$ and a tea yield of $111.65 \times 10^{4} \mathrm{t}$ in 2020 , accounting for $28.79 \%$ of the tea planting area and $18.15 \%$ of the tea yield worldwide, respectively. According to the atlas of soil environmental background value in the People's Republic of China [23], the background values of the southwest region of China are 16.04, 0.240, 76.32, and $42.42 \mathrm{mg} \mathrm{kg}^{-1}$ for As, $\mathrm{Cd}, \mathrm{Cr}$ and $\mathrm{Pb}$, respectively, which are considered as a high HMs (As, Cd, $\mathrm{Cr}$ and $\mathrm{Pb}$ ) geological background in China. Meanwhile, it is also affected by industrial activities, such as partial non-ferrous metal mining and selection, and agricultural activities involving pesticides and fertilizers for tea plantations [12-16]. In recent years, some tea plantation soils $\mathrm{HMs}(\mathrm{As}, \mathrm{Cd}, \mathrm{Cr}$ and $\mathrm{Pb}$ ) have exceeded the risk screening values for the soil contamination of agricultural land (GB15618-2018) in China, and therefore, excessive HMs in tea leaves may not be safe for human consumption [24]. Long-term consumption of HMs-enriched tea leaves may affect the nervous system, liver, and kidney [25]. Thus, the characteristics of HM pollution in the soil-tea system and potential health risks to humans are of increasing concern; accordingly, strict health assessments of the pollution risks are underway. For instance, the HMs assessment of tea leaves from a mining county of Fujian province, China, revealed that the personal total annual risk of oolong tea was slightly higher, while black and green tea were below the maximum acceptable levels of the US EPA $\left(1.0 \times 10^{-4}\right)$ [26].Cao et al. [27] reported that the $\mathrm{HMs}(\mathrm{Pb}, \mathrm{Al}, \mathrm{Cd}, \mathrm{Zn}$, As and $\mathrm{Cu}) \mathrm{HQ}$ (hazard quotient) of raw and fermented Puerh tea from Puer in Yunnan, China, were $<1$, suggesting safe levels for tea consumption. Most of these studies mainly paid attention to clear sources of pollution, such as industrial, mining, smelting, and sewage irrigation, but only a few investigated HMs accumulation in the soil-tea systems of a superimposed high geochemical background area with human activities. The southwest region of China is a high HMs background area with relatively large tea plantation activity; however, the health risks related to the soil-tea system of this area are unknown. 
Accordingly, this study aimed to evaluate the $\mathrm{HMs}(\mathrm{As}, \mathrm{Cd}, \mathrm{Cr}$ and $\mathrm{Pb}$ ) risk in the tea plantation soils and tea leaves from the southwest region of China using the Impact Index of Comprehensive Quality. The corresponding $\mathrm{Cr}, \mathrm{Cd}, \mathrm{Pb}$, and $\mathrm{As}$ contents of soil and tea leaves were quantified and a potential relationship between the soil and tea leaves HMs content was investigated. Furthermore, the health risk assessment model (i.e., Target hazard quotient) was used to evaluate the health risk of long-term tea consumption in adults. These results may help to control HMs pollution in the test region.

\section{Materials and Methods}

\subsection{Study Area}

The study area $\left(114,500 \mathrm{hm}^{2}\right)$, covering a total of 29 counties, is situated in the southwest region of China $\left(97^{\circ} 31^{\prime} \sim 102^{\circ} 39^{\prime} \mathrm{E}, 21^{\circ} 08^{\prime} \sim 25^{\circ} 52^{\prime} \mathrm{N}\right)$. It mainly includes the three cities (prefectures) of Lincang City, Pu'er City, and Xishuangbanna Prefecture, along with some counties and districts of Baoshan City, Dali Prefecture, Honghe Prefecture, and Dehong Prefecture. The local climate is tropical and subtropical monsoon with an average annual temperature and precipitation of $19.5{ }^{\circ} \mathrm{C}$ and $1030.1 \mathrm{~mm}$, respectively. The months from May to October are the peak rainy season. Lao'ai, Wuliang, and Gaoligong mountains are in the north of the study area with an elevation of $<3000 \mathrm{~m}$. The terrain gradually slows to the south and southwest with the broadening of the valley. In the south and southwest, the terrain gradually becomes gentle with the low mountains, wide valley basins, and elevation of about $800-1000 \mathrm{~m}$; elevation in some areas drops to $<500 \mathrm{~m}$. Red soil is the main soil type. The southwest region is the major production area of tea in Yunnan Province, with a yield (dried tea) of $466,000 \mathrm{t}$ in 2020, accounting for $>90 \%$ of the whole province's production.

\subsection{Sample Collection}

Accounting for terrain and tea plantation distribution in southwest Yunnan, 421 pairs of soil and tea leaves samples were collected from 29 major tea-producing counties in the harvest season of September 2020. Each sample included five sub-samples within the $100 \mathrm{~m}^{2}$ of the main sample collection area. Soil samples, after being cleaned of plant roots, animal residues, and large rock fragments, were naturally air-dried, ground, and sieved at $2 \mathrm{~mm}$. Composite samples were stored in a sample bottle until analysis. Meanwhile, the corresponding tea leaves samples (a bud and two leaves) were plucked randomly from each collection site. The tea leaves were rinsed with deionized water thrice, wiped dry, heated at $105^{\circ} \mathrm{C}$ for $30 \mathrm{~min}$, and then at $75^{\circ} \mathrm{C}$ until they reached a constant weight. The dried tea leaves samples were ground and sieved through a $0.149-\mathrm{mm}$ nylon sieve before storage at room temperature (RT) for later analysis. The specific sampling point information is presented in Figure 1. 


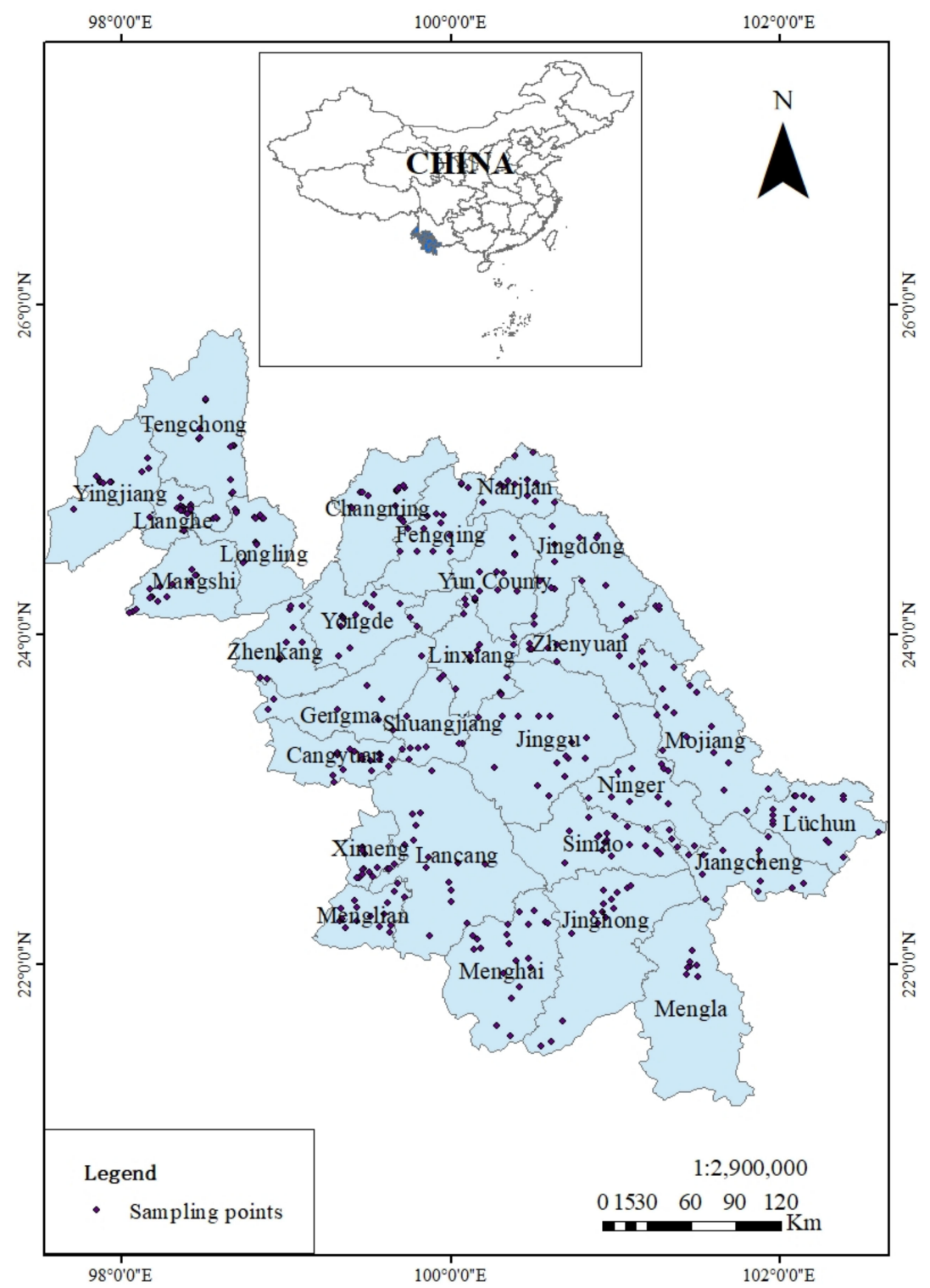

Figure 1. Map of the study area: the southwest region of Yunnan province, China.

\subsection{Risk Assessment Method}

Influence index of comprehensive quality (IICQ), combining the influence index of comprehensive quality for soil $\left(I I C Q_{S}\right)$ and agricultural products $\left(I I C Q_{A P}\right)$, takes into account the standard and valence effect of soil elements, the background value of soil elements, the limit standard of pollutants, and the content of target elements in agricultural products. It mainly comprises the following calculation process.

Determination of contaminating elements and quantities.

The measured values of elements in soil samples were compared with the evaluation standard and background values to find those that exceeded the limit, $X$ and $Y$, respectively. Likewise, the estimated elemental values of agricultural products were compared with the pollutant limit standards for food to determine the Z-value of contaminants that exceeded the limit.

The $X$ value for soil was calculated as follows:

$$
P_{s s i}=P_{i} / S_{i}
$$

where $P_{s s i}$ is the index value of the sample element determination and evaluation criteria. For $P_{s s i} \leq 1$, take $x_{i}=0$; for $P_{s s i}>1$, take $x_{i}=1 ; X$ is the sum of $x_{i}$. 
The $Y$ value for soil was calculated as follows:

$$
P_{S B i}=C_{i} / C_{B i}
$$

where $P_{S B i}$ is the index value of the sample element determination value and the background value. For $P_{S B i} \leq 1$, take $y_{i}=0$; for $P_{S B i}>1$, take $y_{i}=1 ; Y$ is the sum of $y_{i}$.

The $Z$ value for agricultural products was calculated as follows:

$$
P_{A P i}=C_{A P i} / C_{L S i}
$$

where $P_{A P i}$ is the index value of the determination value of elements in agricultural products and the limit value of pollutants in food. $C_{A P i}$ is the concentration of element $i$ in agricultural products, $C_{L S i}$ is the limit standard of element $i$ in agricultural products. For $P_{A P i} \leq 1$, take $z_{i}=0$; for $P_{A P i}>1$, take $z_{i}=1 ; Z$ value is the sum of $y_{i}$.

Relative impact equivalent (RIE) was calculated as follows:

$$
R I E=\left[\sum_{i=1}^{N}\left(P_{s s i}\right)^{1 / n}\right] / N=\left[\sum_{i=1}^{N}\left(C_{i} / C_{s i}\right)^{1 / n}\right] / N
$$

where $N$ is the number of elements, $C_{i}$ is the concentration of element $i, C_{s i}$ is the standard value of soil environmental quality of element $i$; the $\mathrm{Pb}, \mathrm{Cr}, \mathrm{As}$, and $\mathrm{Cd}$ standard values in China (NY/T853-2004) are 250, 150, 40, and $0.3 \mathrm{mg} \mathrm{kg}^{-1}$ for $\mathrm{pH} \leq 6.5$ soil, and 300, 200, 30 , and $0.4 \mathrm{mg} \mathrm{kg}^{-1}$ for $\mathrm{pH}>6.5$ soil, respectively. $n$ is the oxidation number of element $i$ $(\mathrm{Cr}, 3 ; \mathrm{Pb}, 2 ; \mathrm{Cd}, 2$; and $\mathrm{As}, 5)$. A larger RIE value suggests a bigger influence of exogenous substances.

The residue limits of tea leaves for Pb, Cr, As, and Cd (NY695-2003 and GB2762-2017) were $5,5,2$, and $1 \mathrm{mg} \mathrm{kg}^{-1}$, respectively.

The deviation degree of determination concentration from the background value $(D D D B)$ was calculated as follows:

$$
D D D B=\left[\sum_{i=1}^{N}\left(P_{S B i}\right)^{1 / n}\right] / N=\left[\sum_{i=1}^{N}\left(C_{i} / C_{B i}\right)^{1 / n}\right] / N
$$

where $C_{B i}$ is the background value of element $i$ (shown in Table 1), and the other symbols remain the same as above. A larger $D D D B$ value suggests a greater influence of exogenous substances.

The deviation degree of standard from the background value (DDSB) was calculated as follows:

$$
D D S B=\left[\sum_{i=1}^{N}\left(C_{S i} / C_{B i}\right)^{1 / n}\right]
$$

Symbols stay the same as above. A larger $D D D B$ value suggests a greater deviation of soil standard from the background value with the greater load capacity of the soil and stronger buffer to the exogenous substances.

The quality index of agricultural products $(Q I A P)$ was calculated as follows:

$$
Q I A P=\left[\sum_{i=1}^{N}\left(P_{A P i}\right)^{1 / n}\right] / N=\left[\sum_{i=1}^{N}\left(C_{A P i} / C_{L S i}\right)^{1 / n}\right] / N
$$

where $C_{A P i}$ is the concentration of element $i$ in agricultural products, $C_{L S i}$ is the residue limit for element $i$ in agricultural products. The residue limits of tea leaves for $\mathrm{Cd}, \mathrm{Cr}, \mathrm{Pb}$, As (NY695-2003 and GB2762-2017) are 1, 5, 5, and $2 \mathrm{mg} \mathrm{kg}^{-1}$, respectively. QIAP indicates the influence of HMs on the quality of agricultural products. A higher residue limit value of HMs in agricultural products suggests the worsening of quality. 
Table 1. Background values of lead $(\mathrm{Pb})$, chromium $(\mathrm{Cr})$, arsenic (As), and cadmium (Cd) in soils from selected regions.

\begin{tabular}{|c|c|c|c|c|}
\hline \multirow{2}{*}{ Region } & $\mathrm{Pb}$ & $\mathrm{Cd}$ & $\mathrm{Cr}$ & As \\
\hline & \multicolumn{4}{|c|}{$\mathrm{mg} \mathrm{kg}^{-1}$} \\
\hline Tengchong & 39.16 & 0.139 & 58.8 & 7.42 \\
\hline Longling & 39.16 & 0.139 & 58.8 & 7.42 \\
\hline Changning & 39.16 & 0.139 & 58.8 & 7.42 \\
\hline Lianghe & 43.82 & 0.071 & 55.2 & 4.25 \\
\hline Yingjiang & 43.82 & 0.071 & 55.2 & 4.25 \\
\hline Mangshi & 43.82 & 0.071 & 55.2 & 4.25 \\
\hline Fengqing & 39.67 & 0.115 & 75.7 & 13.47 \\
\hline Yongde & 39.67 & 0.115 & 75.7 & 13.47 \\
\hline Zhenkang & 39.67 & 0.115 & 75.7 & 13.47 \\
\hline Linxiang & 39.67 & 0.115 & 75.7 & 13.47 \\
\hline Yun County & 39.67 & 0.115 & 75.7 & 13.47 \\
\hline Gengma & 39.67 & 0.115 & 75.7 & 13.47 \\
\hline Cangyuan & 39.67 & 0.115 & 75.7 & 13.47 \\
\hline Shuangjiang & 39.67 & 0.115 & 75.7 & 13.47 \\
\hline Nanjian & 34.16 & 0.128 & 68.7 & 8.39 \\
\hline Jingdong & 32.83 & 0.060 & 59.0 & 8.77 \\
\hline Zhenyuan & 32.83 & 0.060 & 59.0 & 8.77 \\
\hline Jinggu & 32.83 & 0.060 & 59.0 & 8.77 \\
\hline Lancang & 32.83 & 0.060 & 59.0 & 8.77 \\
\hline Ximeng & 32.83 & 0.060 & 59.0 & 8.77 \\
\hline Menglian & 32.83 & 0.060 & 59.0 & 8.77 \\
\hline Mojiang & 32.83 & 0.060 & 59.0 & 8.77 \\
\hline Jiangcheng & 32.83 & 0.060 & 59.0 & 8.77 \\
\hline Ninger & 32.83 & 0.060 & 59.0 & 8.77 \\
\hline Simao & 32.83 & 0.060 & 59.0 & 8.77 \\
\hline Menghai & 25.80 & 0.061 & 49.8 & 9.15 \\
\hline Jinghong & 25.80 & 0.061 & 49.8 & 9.15 \\
\hline Mengla & 25.80 & 0.061 & 49.8 & 9.15 \\
\hline Lüchun & 41.24 & 0.099 & 72.4 & 14.65 \\
\hline
\end{tabular}

The influence index of comprehensive quality (IICQ) was calculated as follows.

$$
\begin{gathered}
I I C Q_{S}=X \times(1+R I E)+Y \times(D D D B) / D D S B \\
I I C Q_{A P}=Z \times(1+Q I A P / k)+Q I A P /(k \times D D S B)
\end{gathered}
$$

Namely,

$$
\begin{gathered}
I I C Q=I I C Q_{S}+I I C Q_{A P} \\
=[X \times(1+R I E)+Y \times(D D D B) / D D S B]+[Z \times(1+Q I A P / k) \\
+Q I A P /(k \times D D S B)
\end{gathered}
$$

where IICQ $Q_{s}$ and IICQ $Q_{A P}$ are the influence index of comprehensive quality for soil and agricultural products, respectively. $X$ and $Y$ are the numbers of measured values that exceeded soil standard and background values, respectively. $Z$ is the quantities of measured values that exceeded the threshold limit of agricultural products. $k$ is the correction parameter of background, which was set to 5 for food safety.

Based on the sum of IICQ $Q_{s}$ and IICQ $Q_{A P}$ in a region, the soil-tea system HMs pollution risk was categorized into the following 5 grades: $<1$, uncontaminated; $1-2$, slightly contaminated; $2-3$, moderately contaminated; $3-5$, heavily contaminated, and above 5 , extremely contaminated.

\subsection{Health Risk Assessment Method}

Target hazard quotient (THQ) was established by the United States Environmental Protection Agency (EPA) in 2000 to assess the non-carcinogenic risk of human exposure 
to pollutants such as HMs. It assumes the absorbed dose of pollutants equal to the intake dose and uses the ratio of human absorbed dose of pollutants to the reference dose for evaluation. Here, we only calculated the exposure risk of tea intake and did not consider any other routes of exposure. THQ was calculated using the following formula:

$$
T H Q=\frac{E_{F} \times E_{D} \times F_{I R} \times c}{R f d \times W_{A B} \times T_{A}} \times 10^{-3}
$$

where $E_{F}$ is the exposure frequency in adults, $350 \mathrm{~d} \mathrm{a}^{-1} ; E_{D}$ is the exposure duration, $24 \mathrm{a} ; F_{I R}$ is the daily tea intake rate, $0.0094 \mathrm{~kg} \mathrm{~d}^{-1} ; \mathrm{c}$ is the average content of HMs in tea, $\mathrm{mg} \mathrm{kg}^{-1}$; Rfd is the daily allowance for HMs such as $0.0035,0.001,0.003$ and 0.0003 for lead, cadmium, chromium, and arsenic, respectively. $W_{A B}$ is the average weight of an adult, $56.8 \mathrm{~kg}$. $T_{A}$ is the average exposure time (set to 350 days $\times 24$ years) for non-carcinogens. A THQ value less than 1 indicates an acceptable risk of HMs exposure from tea; on the contrary, a higher $T H Q$ value suggests increased risk to human health.

The impact of HMs on human health is a combined action of multiple elements; the composite risk of multiple heavy metals was calculated using the following formula:

$$
H I=\sum T H Q(\text { sing pollutant })
$$

where $H I$ is the hazard index. $H I<1, H I>1$, and $H I>10$ indicate no obvious negative impact, a high possibility of negative effects, and chronic toxicity, respectively.

\subsection{Sample Analysis}

Soil $\mathrm{pH}$ was determined as per the glass electrode method (liquid comprised of 1:2.5 $w / v$ ) [28], and the soil organic matter was determined as per the external heating method using potassium dichromate [28]. Soil $\mathrm{HMs}(\mathrm{Pb}, \mathrm{Cr}, \mathrm{As}$, and $\mathrm{Cd}$ ) were digested with concentrated nitric, hydrochloric, and hydrofluoric acids using a microwave digestion apparatus (Multiwave 5000, Anton Paar, Austria) following the HJ832-2017 method in China. $\mathrm{Pb}$ and $\mathrm{Cd}$ in digested soil solution were determined using Graphite furnace atomic absorption spectrophotometry (GFAAS, PerkinElmer 900H, PerkinElmer, Akron, $\mathrm{OH}, \mathrm{USA}$ ). As and $\mathrm{Cr}$ were determined using atomic fluorescence spectrometry (AFS-933, Titan Instrument, Beijing, China) and flame atomic absorption spectrophotometry (FAAS, PerkinElmer 900H, PerkinElmer, Akron, OH, USA), respectively.

$\mathrm{HMs} \mathrm{Pb}, \mathrm{As}$, and $\mathrm{Cr}$ in tea leaves samples were digested with concentrated nitric acid using a microwave digestion apparatus (Multiwave 5000, Anton Paar, Austria) following the respective GB5009.12, GB 5009.11, and GB 5009.123 methods in China. Cd in tea leaves was digested with concentrated nitric acid and $30 \% \mathrm{H}_{2} \mathrm{O}_{2}$ according to the GB5009.15 method in China. The $\mathrm{Cr}, \mathrm{Cd}$, and $\mathrm{Pb}$ in the digested liquids were measured utilizing GFAAS, while As was measured using inductively coupled plasma mass spectrometry (ICP-MS, Qc, Thermo Fisher, Waltham, MA, USA).

For the soil sample analytical method, the limits of detection values (LODs) for $\mathrm{Pb}$, $\mathrm{Cr}$, As, and Cd were $0.1,4.0,0.01,0.01 \mathrm{mg} \mathrm{kg}^{-1}$, respectively. Likewise, for the tea leaves sample determination method, LODs for $\mathrm{Pb}, \mathrm{Cr}$, As, and $\mathrm{Cd}$ were 0.02, 0.01, 0.002, and $0.001 \mathrm{mg} \mathrm{kg}^{-1}$, respectively. Furthermore, a certified reference soil (GBW07451) and tea leaves material (GBW08513) from the National Research Center for standard materials in China were used for quality control of the sample batch. The concentrations of measured reference materials were within the certified ranges; the average recoveries for $\mathrm{Pb}, \mathrm{Cr}, \mathrm{As}$, and $\mathrm{Cd}$ were 98.2, 103.0, 92.5, and 93.5\% for soils, and 94.7, 104.0, 101.0, and 98.2\% for tea leaves, respectively. All determinations were conducted thrice to ensure the data quality.

\subsection{Data Analysis}

All statistical procedures were performed using the Origin 9.0 (Origin Lab Corporation, Northampton, MA, USA) and Excel 2007 (Microsoft, Redmond, WA, USA) programs. The spatial distribution map and Kriging interpolation map were prepared using ArcGIS10.2 
(Esri, Redlands, CA, USA). Before the data analysis, survey data were checked for normal distribution.

\section{Results}

\subsection{Heavy Metals in Soils and Tea Leaves}

Descriptive statistics for soil HMs contents from the southwest region of Yunnan province, China, are shown in Figure 2a. The average amounts of $\mathrm{Pb}\left(3.2\right.$ to $\left.387 \mathrm{mg} \mathrm{kg}^{-1}\right)$, $\mathrm{Cd}\left(0.03\right.$ to $\left.7.94 \mathrm{mg} \mathrm{kg}^{-1}\right), \mathrm{Cr}$ ( 6 to $\left.600 \mathrm{mg} \mathrm{kg}^{-1}\right)$, and As $\left(0.01\right.$ to $153 \mathrm{mg} \mathrm{kg}^{-1}$ ) were 29.27, $0.18,79.06,14.87 \mathrm{mg} \mathrm{kg}^{-1}(n=421)$, respectively; the numbers in parentheses show the range. Additionally, $0.71,10.21,4.99$, and $7.36 \%$ of soil samples exceeded the threshold values (NY/T 853-2004) of $\mathrm{Pb}, \mathrm{Cd}, \mathrm{Cr}$, and As, respectively.
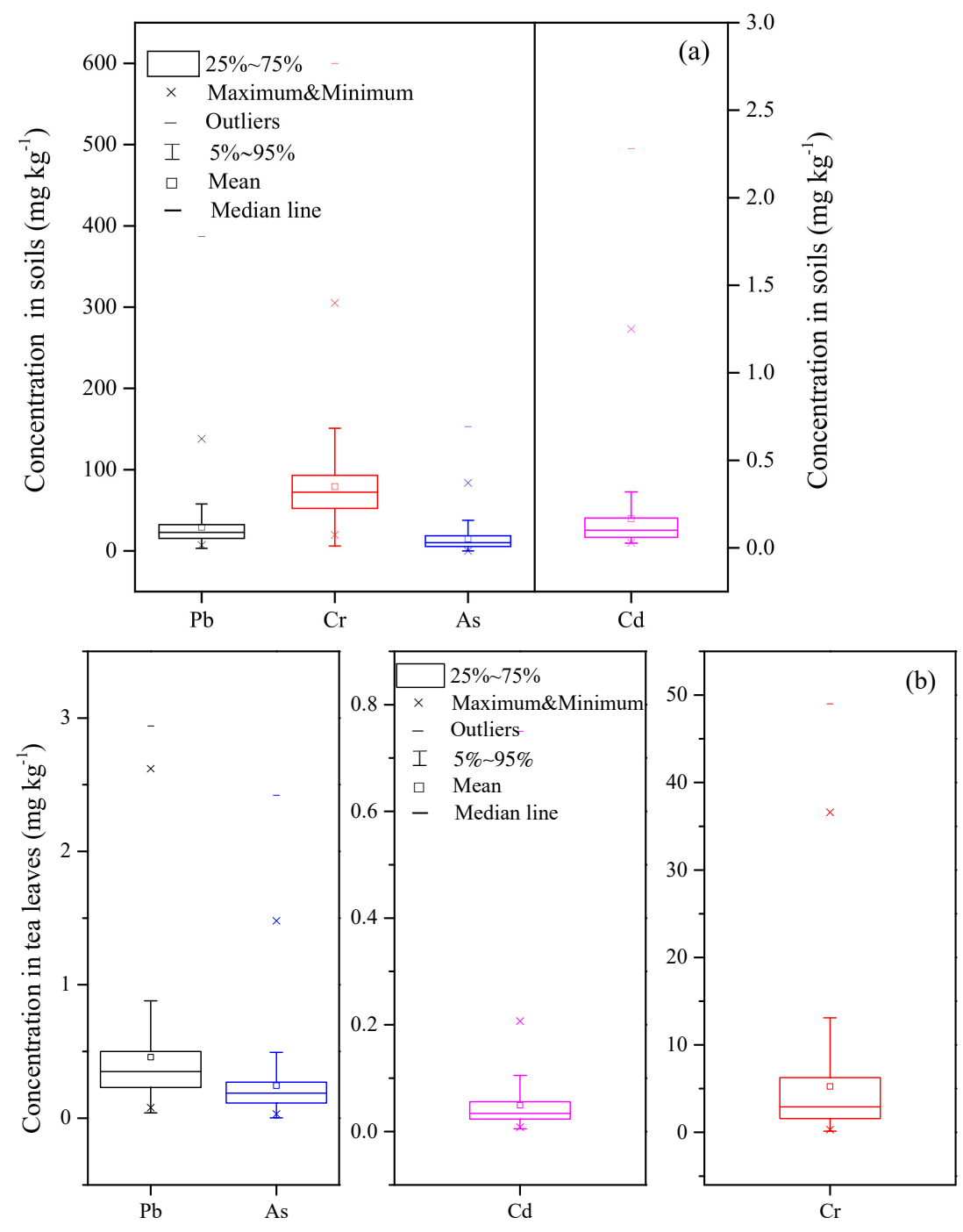

Figure 2. Contents of $\mathrm{Pb}, \mathrm{Cr}, \mathrm{As}$, and $\mathrm{Cd}$ in soil (a) and tea leaves (b) samples. The standard values in China (NY/T853-2004) for Pb, Cr, As, and Cd are 250, 150, 40, and $0.3 \mathrm{mg} \mathrm{kg}^{-1}$ for $\mathrm{pH} \leq 6.5$ soil, and $300,200,30$, and $0.4 \mathrm{mg} \mathrm{kg}^{-1}$ for $\mathrm{pH}>6.5$ soil. The residue limits values of tea leaves (NY695-2003 and GB2762-2017) for $\mathrm{Pb}, \mathrm{Cr}$, As, and Cd are 5, 5, 2, and $1 \mathrm{mg} \mathrm{kg}^{-1}$, respectively.

Likewise, the HMs contents in the tea leaves from the southwest region of Yunnan province, China, are presented in Figure $2 \mathrm{~b}$. The average amounts of $\mathrm{Pb}(0.04$ to $\left.2.90 \mathrm{mg} \mathrm{kg}^{-1}\right), \mathrm{Cd}\left(0.005\right.$ to $\left.0.620 \mathrm{mg} \mathrm{kg}^{-1}\right), \mathrm{Cr}\left(0.13\right.$ to $\left.49.0 \mathrm{mg} \mathrm{kg}^{-1}\right)$, and as (0.001 to $\left.2.42 \mathrm{mg} \mathrm{kg}^{-1}\right)$ were $0.46,0.05,5.28,0.25 \mathrm{mg} \mathrm{kg}^{-1}(n=421)$, respectively; the numbers in 
parentheses show the range. $\mathrm{Pb}$, As and $\mathrm{Cd}$ were below the set limits, while $\mathrm{Cr}$ exceeded the amounts set by the Ministry of Agriculture of China (NY659-2003 and GB2762-2017).

\subsection{Correlation Analysis}

The relationship between the total concentrations of HMs in soil and tea leaves is shown in Figure 3. The amounts of $\mathrm{Pb}, \mathrm{Cr}, \mathrm{As}$, and $\mathrm{Cd}$ in the tea leaves positively correlated with their amounts in the soil $(p<0.01)$ with an $R^{2}$ of $0.203^{* *}, 0.074^{* *}, 0.036^{* *}, 0.090^{* *}$, respectively. Further statistical analysis revealed that the correlations between the soil and tea leaves HMs amounts were as follows: $\mathrm{Pb}>\mathrm{As}>\mathrm{Cd}>\mathrm{Cr}$. This suggests that the increase in the total HMs concentration in the soil has a certain effect on the absorption and accumulation of HMs in tea leaves, but it is not the main factor.

\subsection{Collaborative Assessment}

A collaborative assessment of the HMs in soils and tea leaves from the southwest region of Yunnan province is shown in Table S1. Among the 421 collected samples, 80.05, $6.18,10.69,1.19$, and $1.90 \%$ of the soil samples were found as uncontaminated, slightly contaminated, moderately contaminated, heavily contaminated, and extremely contaminated, respectively. Correspondingly, $71.50 \%$ of the tea leaves samples were contaminated; only 28.03 and $0.48 \%$ of the tea leaves samples were slightly or moderately contaminated.

The Influence Index of Comprehensive Quality (IICQ), the collaborative assessment of HMs in soils and tea leaves, broadly considers soil quality and food safety (Table S1). We found that 59.62, 24.47, 7.60, 5.70, and $2.61 \%$ of the samples were uncontaminated, slightly contaminated, moderately contaminated, heavily contaminated, and extremely contaminated, respectively. A spatial distribution map of the collaborative assessment of HMs was created using geostatistical methods, ordinary Kriging in GIS (Figure 4). We found that the moderately contaminated (high IICQ blocks; yellow color) samples were from Lancang County, the southwest of the study region, while the slightly contaminated (light green color blocks) were scattered to Yingjiang, Zhenkang, Yongde, Zhenyuan, Lüchun, Jingdong, Ximeng, and Menglian.

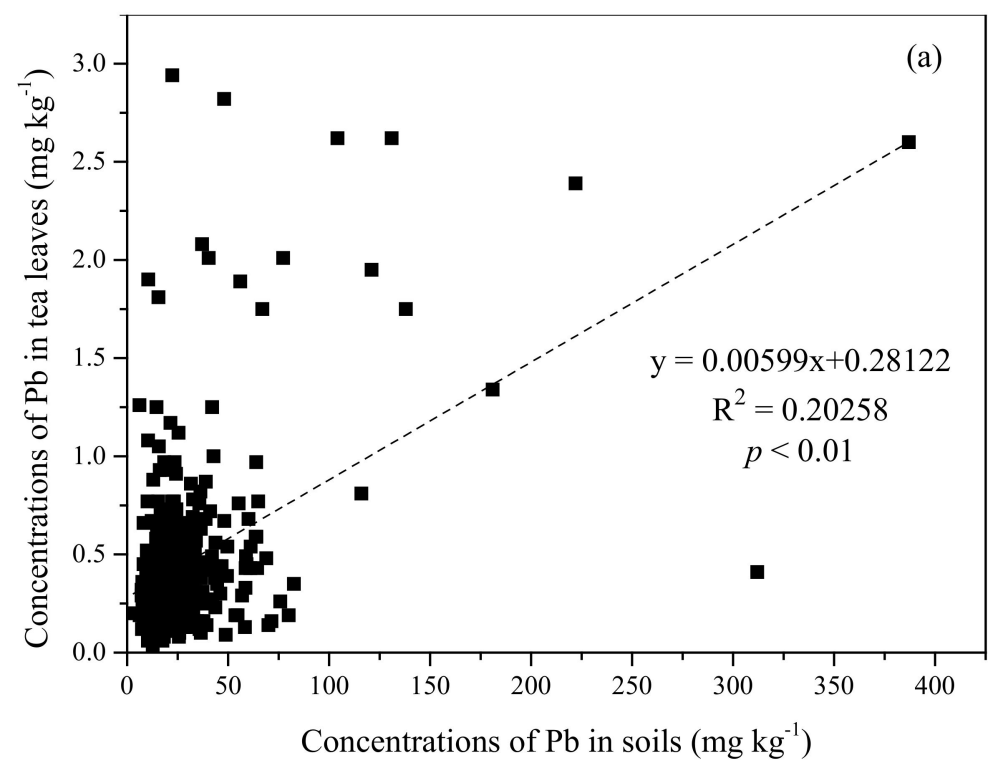

Figure 3. Cont. 

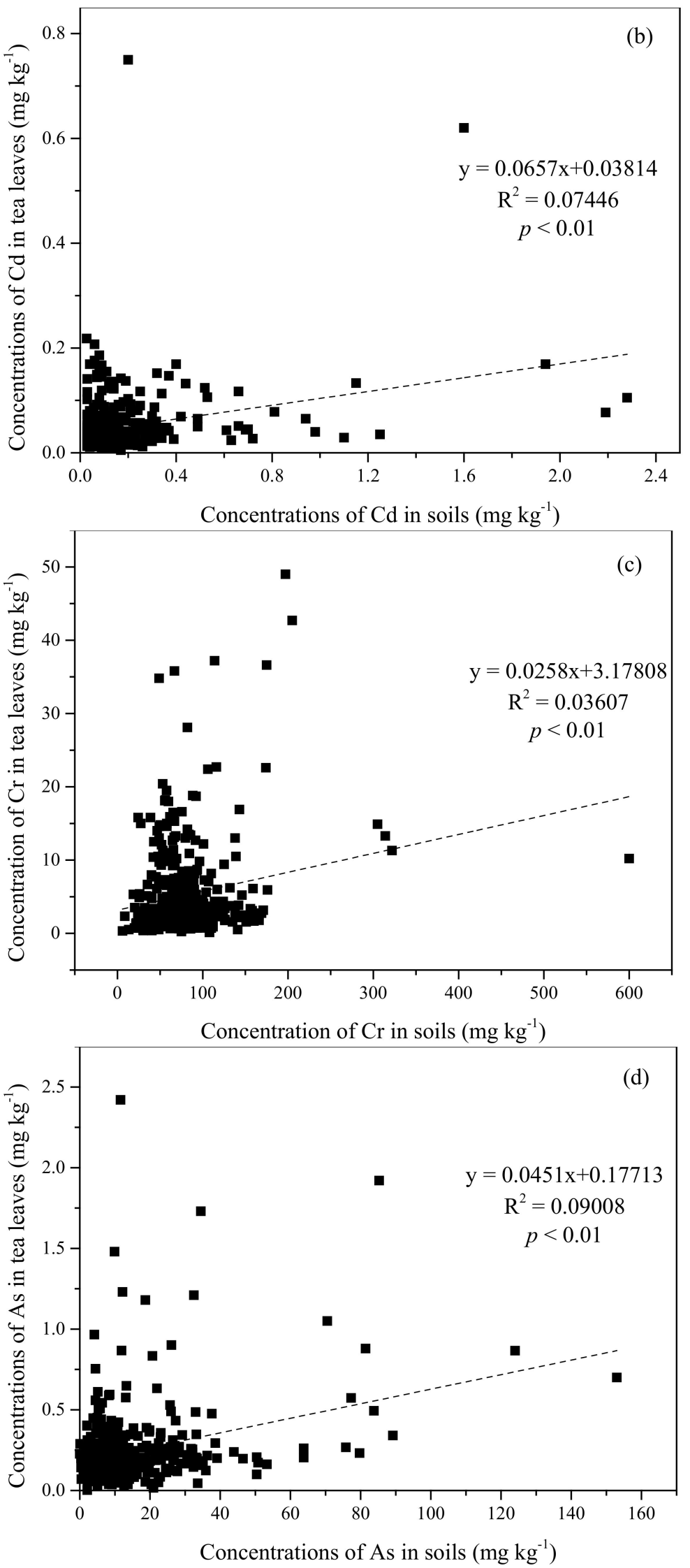

Figure 3. The relationship between the concentrations of heavy metals (i.e., (a) $\mathrm{Pb}$, (b) $\mathrm{Cd}$, (c) $\mathrm{Cr}$, and (d) As) in soil and corresponding tea leaves. Sample size $=421$. 


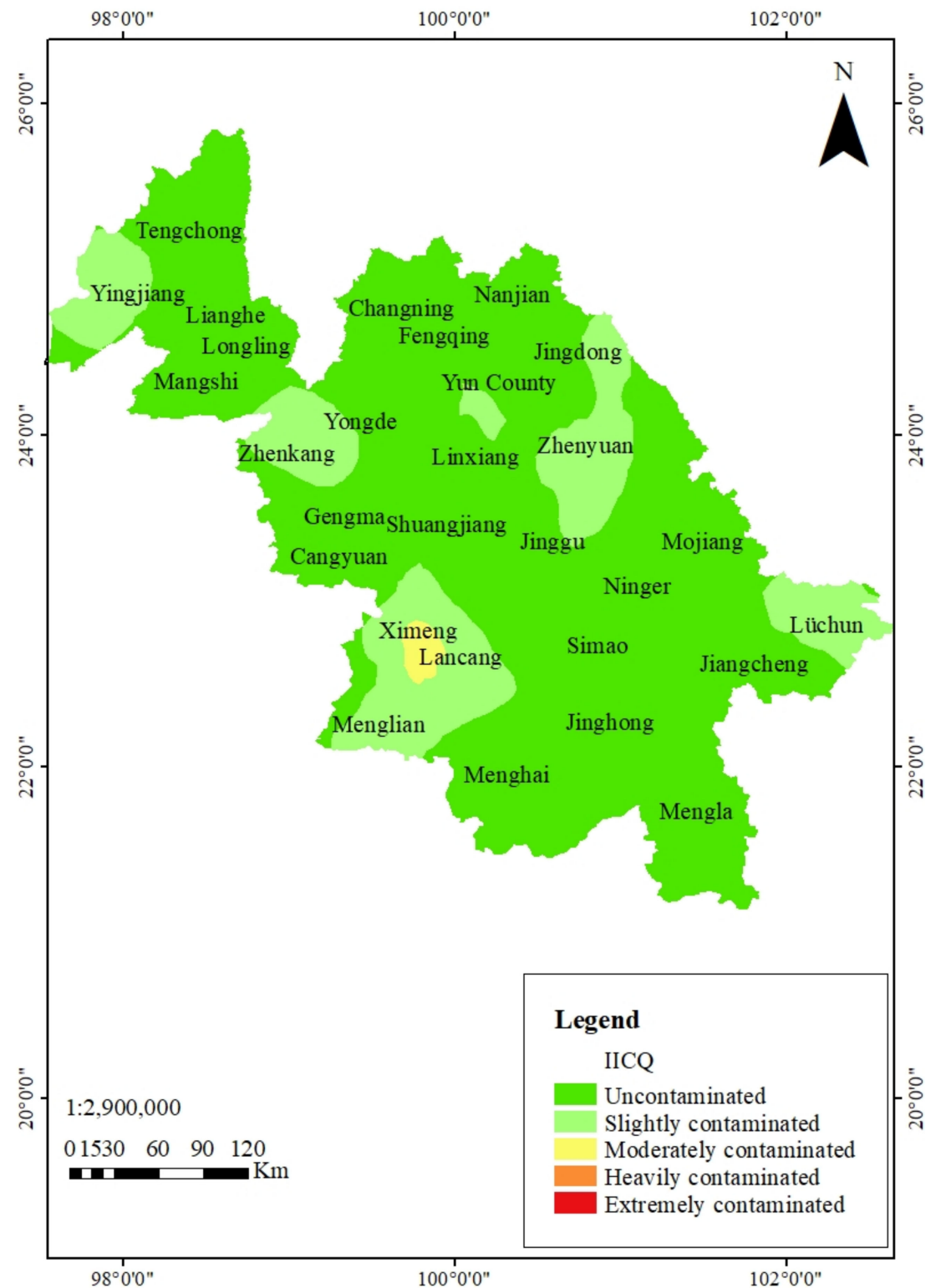

Figure 4. Prediction map of the potential risk of heavy metal contamination in tea plantation areas based on the collaborative assessment. IICQ denotes the overall quality of soil and tea leaves divided into 5 grades: below 1 , uncontaminated; $1-2$, slightly contaminated; $2-3$, moderately contaminated; $3-5$, heavily contaminated; and $>5$, extremely contaminated.

\subsection{Health Risk Assessment}

The target hazard quotient method was used to assess the health risk associated with the consumption of HMs-contaminated tea leaves in adults (Table 2). The corresponding $T H Q$ values for $\mathrm{Pb}, \mathrm{Cr}$, As, and $\mathrm{Cd}$ were $0.021,0.288,0.136$, and 0.007 , respectively. Based on the mean THQ, the order of HMs contamination was $\mathrm{Cr}>\mathrm{As}>\mathrm{Pb}>\mathrm{Cd}$; the risk index was less than one. This suggests that exposure to a single $\mathrm{HM}$ via tea consumption is not a potential health risk to adults. 
Table 2. The calculated target hazard quotients (THQ) of $\mathrm{Pb}, \mathrm{Cd}, \mathrm{Cr}$, and As, and hazard index (HI) for adults associated with the tea leaves consumption in the southwest region of Yunnan province, China.

\begin{tabular}{|c|c|c|c|c|c|}
\hline \multirow{2}{*}{ Region } & \multicolumn{5}{|c|}{ Risk Assessment Index } \\
\hline & $T H Q_{\mathrm{Pb}}$ & $T H Q_{\mathrm{Cd}}$ & $T H Q_{\mathrm{Cr}}$ & $T H Q_{\text {As }}$ & $H I$ \\
\hline Tengchong & 0.020 & 0.002 & 0.044 & 0.093 & 0.159 \\
\hline Longling & 0.020 & 0.005 & 0.175 & 0.098 & 0.298 \\
\hline Changning & 0.018 & 0.004 & 0.200 & 0.134 & 0.356 \\
\hline Lianghe & 0.029 & 0.003 & 0.090 & 0.145 & 0.268 \\
\hline Yingjiang & 0.014 & 0.002 & 0.135 & 0.168 & 0.319 \\
\hline Mangshi & 0.017 & 0.006 & 0.242 & 0.152 & 0.416 \\
\hline Fengqing & 0.020 & 0.007 & 0.141 & 0.083 & 0.251 \\
\hline Yongde & 0.016 & 0.010 & 0.298 & 0.083 & 0.407 \\
\hline Zhenkang & 0.013 & 0.022 & 0.794 & 0.152 & 0.980 \\
\hline Linxiang & 0.024 & 0.009 & 0.196 & 0.118 & 0.347 \\
\hline Yun County & 0.039 & 0.009 & 0.108 & 0.153 & 0.308 \\
\hline Gengma & 0.011 & 0.013 & 0.065 & 0.054 & 0.143 \\
\hline Cangyuan & 0.019 & 0.008 & 0.251 & 0.072 & 0.350 \\
\hline Shuangjiang & 0.020 & 0.008 & 0.128 & 0.104 & 0.260 \\
\hline Nanjian & 0.019 & 0.004 & 0.435 & 0.140 & 0.599 \\
\hline Jingdong & 0.012 & 0.011 & 0.209 & 0.109 & 0.341 \\
\hline Zhenyuan & 0.033 & 0.010 & 0.548 & 0.195 & 0.786 \\
\hline Jinggu & 0.011 & 0.005 & 0.215 & 0.138 & 0.369 \\
\hline Lancang & 0.040 & 0.010 & 0.538 & 0.225 & 0.814 \\
\hline Ximeng & 0.019 & 0.004 & 0.538 & 0.170 & 0.730 \\
\hline Menglian & 0.012 & 0.009 & 0.523 & 0.165 & 0.710 \\
\hline Mojiang & 0.034 & 0.009 & 0.259 & 0.222 & 0.523 \\
\hline Jiangcheng & 0.015 & 0.005 & 0.287 & 0.083 & 0.390 \\
\hline Ninger & 0.012 & 0.013 & 0.165 & 0.079 & 0.269 \\
\hline Simao & 0.016 & 0.006 & 0.274 & 0.133 & 0.429 \\
\hline Menghai & 0.027 & 0.005 & 0.583 & 0.255 & 0.870 \\
\hline Jinghong & 0.015 & 0.005 & 0.350 & 0.084 & 0.453 \\
\hline Mengla & 0.024 & 0.006 & 0.191 & 0.214 & 0.435 \\
\hline Lüchun & 0.029 & 0.007 & 0.217 & 0.086 & 0.338 \\
\hline Study area & 0.021 & 0.007 & 0.288 & 0.136 & 0.452 \\
\hline
\end{tabular}

Note: $T H Q_{\mathrm{Pb}}, T H Q_{\mathrm{Cd}}, T H Q_{\mathrm{Cr}}, T H Q_{\mathrm{As}}$ are the target hazard quotients values of $\mathrm{Pb}, \mathrm{Cd}, \mathrm{Cr}$, and $\mathrm{As}$, respectively, and $H I$ is the hazard index values.

The $H I$ is a useful parameter to evaluate overall potential health risk from multiple HMs consumption. The $H I$ values, with an average value of 0.452 (range: 0.159 to 0.980 ), from all the southwest region counties of Yunnan province, China, were less than unity. This suggests that the HMs from tea consumption were not a non-carcinogenic risk.

\section{Discussion}

\subsection{HMs Contents in the Soil-Tea System}

The HMs enrichment of tea plantation soils can be from both natural (e.g., high soil HM geochemical background) and human sources (e.g., mining activities, application of chemical fertilizers, and pesticides containing HMs) [12-16]. In this study, we found that the environmental quality of tea plantation soils from the southwest region of Yunnan province, China, was largely good; however, $0.71,4.99,7.36$, and $10.21 \%$ of the soil samples exceeded the threshold values (NY/T 853-2004) for $\mathrm{Pb}, \mathrm{Cr}$, As, and Cd, respectively. This indicated a soil HMs accumulation in some regions. The average HMs content in tea plantation soil was compared to different previously reported locations worldwide (Table S1). The mean concentrations of $\mathrm{Cr}, \mathrm{As}, \mathrm{Cd}$ were slightly higher, while the $\mathrm{Pb}$ amounts were in the moderate range. The high soil geochemical background of $\mathrm{Cr}$, As and $\mathrm{Cd}$ in the southwest region of Yunnan province is the most significant factor to soil HMs contamination. 
The HMs enrichment of tea leaves is a complicated process affected by the soil HMs content, the bioconcentration coefficient of tea leaves, and the soil physic-chemical properties [17]. In our case, the soil HMs content appears to be an important factor; notably, it showed a positive correlation with the corresponding HMs in tea leaves at $p<0.01$ levels. This is consistent with Zhang et al. [10] suggesting Cd amounts in tea leaves were linked to $\mathrm{Cd}$ content in tea plantation soils. Other studies reported similar findings for other metals, such as Mn, Cr, Se, and Tl [10,12]. For example, Li et al. [29] reported that Se content in rice seeds was weakly positively correlated with the total Se content in the corresponding root-soil $\left(\mathrm{R}^{2}\right.$ 0.0435; $\left.p<0.01\right)$. In our study, the average values $\left(\mathrm{mg} \mathrm{kg}^{-1}\right)$ of $\mathrm{Pb}(0.46), \mathrm{Cd}$ (0.05), and As (0.25) were below the corresponding residue limits, while Cr (5.28) was above the prescribed limits. This indicated that the HMs in the tea leaves were overall in a safe range. A higher $\mathrm{Cr}$ content in the tea leaves may be linked to its relatively high abundance in the soils ( 6 to $600 \mathrm{mg} \mathrm{kg}^{-1}$ ) compared to other reported locations worldwide. In addition, the dustfall, with HMs increasing tea leaves absorption through wet-dry atmospheric deposition, can also be a potential pollution source [30]. Thus, it is necessary to assess in detail the severity of soil contamination and tea leaves safety in the southwest region of China.

\subsection{Comprehensive Evaluation of the Overall Quality of Soils and Tea Leaves}

In this study, we used IICQ to assess the impacts of HMs contamination in the soiltea system [22]. It reflects the interaction between soil and agricultural product heavy metal for farmland soil environmental quality, while considering the ion impulse and HM loading capacity of the soil. Compared with classic evaluation methods, including the single factor index [18], the potential ecological risk index [19], geo-accumulation [20], and the Nemerow comprehensive index [21], it is more objective and reliable. Based on IICQ analysis, we found that 59.62, 24.47, 7.60, 5.70, and $2.61 \%$ of the samples were uncontaminated, slightly contaminated, moderately contaminated, heavily contaminated, and extremely contaminated, respectively. This indicated that the environmental quality of soils and tea leaves from the southwest region of Yunnan province, China, was generally well, while $\sim 40.38 \%$ of the plantation area was contaminated by one or more HM(s). The contaminated areas need urgent remediation due to the severe safety risk of tea leaves, and human health.

Moreover, the spatial distribution map of the collaborative assessment of HMs revealed moderate contamination in Lancang County in the southwest of the study region, while Yingjiang, Zhenkang, Yongde, Zhenyuan, Lüchun, Jingdong, Ximeng, and Menglian were slightly contaminated. There could be several possible explanations for this spatial distribution of HMs. Firstly, Lancang County, which is rich in $>30$ kinds of metal and non-metallic minerals such as iron, $\mathrm{Pb}-\mathrm{Zn}$, lignite, etc., shows high tea leaves enrichment of $\mathrm{Pb}, \mathrm{Cd}$, and As, possibly from their high soil amounts due to the mining, smelting, and rolling of $\mathrm{Pb}-\mathrm{Zn}$ mining. Second, the slight and moderate levels of pollution could be from the application of chemical fertilizers and pesticides, which leads to HMs enrichment in tea leaves. The third possible reason could be high mean geochemical background values (mg kg ${ }^{-1}$ ) for $\mathrm{Pb}$ (36.12), Cr (63.04), As (9.69), and Cd (0.09), respectively [23]. Therefore, both high geochemical background and human activities can be contributors to the HMs contamination of tea plantation soils.

\subsection{Risk of Adult Exposure to Drinking Tea}

Soil HMs can reach into tea trees through the root system and accumulate in different organs and tissues [5]. A large accumulation of HMs in tea leaves [31,32] can endanger human health through tea drinking [33]. The toxicities of $\mathrm{Pb}, \mathrm{Cd}, \mathrm{Cr}$, and As are recognized as major human health risks worldwide [34,35]. With increasing health awareness, the HM contamination in tea leaves has emerged as a great concern. It is unknown whether tea planting areas with a high heavy metal background will pose a threat to human health. In this study, we found that the health risk index for a single heavy metal $(\mathrm{Pb}, \mathrm{Cd}, \mathrm{Cr}$, and $\mathrm{As})$ 
was less than unity in adults, suggesting safe levels. The mean THQ of different metals were $\mathrm{Cr}>\mathrm{As}>\mathrm{Pb}>\mathrm{Cd}$, which indicated that $\mathrm{Cr}$ contamination, with 6.24 to $96.17 \%$ of TTHQ, was the major health risk. The is in line with Wang et al. [26] showing Cr in tea leaves was the major health risk in a mining county of central Fujian province. Other studies reported similar findings for Pu'er and black tea [27,36]. Therefore, $\mathrm{Cr}$ contamination in tea leaves needs special attention and prevention measures, such as spraying leaf tissue control agents to reduce $\mathrm{Cr}$ absorption in tea leaves [37] and finding tea varieties with a reduced risk of $\mathrm{Cr}$ accumulation [26].

In this study, for the southwest region of Yunnan province, China, the hazard index (HI) for HMs ranged from 0.159 to 0.980 , with an average value of 0.452 ; all the counties had $H I$ values less than unity. This suggested no non-carcinogenic risk for adults from tea leaves consumption. A study conducted in the high geological background (for $\mathrm{Tl}, \mathrm{Cd}, \mathrm{As}$, $\mathrm{Sb}, \mathrm{Pb}, \mathrm{Cr}, \mathrm{Hg}$, and $\mathrm{Ni}$ ) of Guizhou province also found a $\mathrm{HI}$ below unity [10]. Additionally, Shen et al. [4] reported that the HI of the daily consumption of black tea, oolong tea, and green tea was low without any health risks. Although the health risk of HMs ingestion via tea leaves is relatively low, there could be other pathways that may expose HMs to humans. Therefore, more comprehensive investigations are needed for a health risk assessment.

\section{Conclusions}

We found that $0.71,4.99,7.36$, and $10.21 \%$ of the soil samples from the southwest region of Yunnan province, China, exceeded the threshold values (NY/T 853-2004) for Pb, $\mathrm{Cr}$, As, and $\mathrm{Cd}$, respectively. The average concentrations of $\mathrm{Pb}, \mathrm{As}$, and $\mathrm{Cd}$ in tea leaves were less than the corresponding residue limits (NY659-2003 and GB2762-2017), but the mean concentration of $\mathrm{Cr}$ was above the corresponding threshold. Correlation analysis revealed that the amounts of $\mathrm{Pb}, \mathrm{Cr}$, As, and $\mathrm{Cd}$ in the tea leaves positively correlated with the corresponding soil amounts. The collaborative assessment indicated that the overall environmental quality of soils and tea leaves from the southwest area was good, while $\sim 40.38 \%$ of the area was contaminated by one more HM. Furthermore, spatial distribution analysis revealed that Lancang was moderately contaminated, while Yingjiang, Zhenkang, Yongde, Zhenyuan, Lüchun, Jingdong, Ximeng, and Menglian were slightly contaminated regions. The $T H Q$ of $\mathrm{Pb}, \mathrm{Cr}, \mathrm{As}$, and $\mathrm{Cd}$, and the $\mathrm{HI}$ indicated no non-carcinogenic risk to adults from tea consumption. Our data may help to control the HMs pollution in tea plantation soil to ensure the quality and safety of tea leaves in the test region.

Supplementary Materials: The following are available online at https:/ /www.mdpi.com/article/10 .3390 /ijerph181910151/s1, Table S1: The concentration of heavy metals in tea plantation soil from different areas. Table S2: The calculation of parameter for collaborative assessment. Table showing the concentration of heavy metals in tea plantation soil from the different areas; table showing the parameters of collaborative assessment.

Author Contributions: J.L. and W.L. contributed to data analysis and writing the manuscript; N.Z. and K.H. supervised, reviewed, and edited the manuscript; D.S., L.Z. and H.D. investigation. All authors have read and agreed to the published version of the manuscript.

Funding: This research was funded by the Yunnan Joint Funds of the National Natural Science Foundation of China, grant number U2002210).

Institutional Review Board Statement: Not applicable.

Informed Consent Statement: Not applicable.

Data Availability Statement: Not applicable.

Acknowledgments: This study was financially supported by the Yunnan Joint Funds of the National Natural Science Foundation of China (Grant No. U2002210). We are grateful to editors and reviewers for their constructive comments and suggestions.

Conflicts of Interest: The authors report no conflicts of interest. 


\section{References}

1. Li, L.H.; Fu, Q.L.; Achal, V.; Liu, Y.L. A comparison of the potential health risk of aluminum and heavy metals in tea leaves and tea infusion of commercially available green tea in Jiangxi, China. Environ. Monit. Assess. 2015, 187, 228. [CrossRef] [PubMed]

2. Gorur, F.K.; Keser, R.; Akcay, N.; Dizman, S.; Okumusoglu, N.T. Radionuclides and heavy metals concentrations in Turkish market tea. Food Control. 2011, 22, 2065-2070. [CrossRef]

3. Zhang, J.; Yang, R.D.; Chen, R.; Peng, Y.S.; Wen, X.F.; Gao, L. Accumulation of heavy metals in tea leaves and potential health risk assessment: A case study from puan county, Guizhou province, China. Int. J. Environ. Res. Public Health 2018, 15, 133. [CrossRef] [PubMed]

4. Shen, F.M.; Chen, H.W. Element composition of tea leaves and tea infusions and its impact on health. Bull. Environ. Contam. Toxicol. 2008, 80, 300-304. [CrossRef]

5. Brzezicha-Cirocka, J.; Grembecka, M.; Szefer, P. Monitoring of essential and heavy metals in green tea from different geographical origins. Environ. Monit. Assess. 2016, 188, 183. [CrossRef] [PubMed]

6. Khan, S.; Aijun, L.; Zhang, S.; Hu, Q.; Zhu, Y.G. Accumulation of polycyclic aromatic hydrocarbons and heavy metals in lettuce grown in the soils contaminated with long-term wastewater irrigation. J. Hazard. Mater. 2008, 152, 506-515. [CrossRef]

7. Kumar Sharma, R.; Agrawal, M.; Marshall, F. Heavy metal contamination of soil and vegetables in suburban areas of Varanasi, India. Ecotoxicol. Environ. Saf. 2007, 66, 258-266. [CrossRef]

8. Nkansah, M.A.; Opoku, F.; Ackumey, A.A. Risk assessment of mineral and heavy metal content of selected tea products from the Ghanaian market. Environ. Monit. Assess. 2016, 188, 332. [CrossRef]

9. Krejpcio, Z.; Sionkowski, S.; Bartela, J. Safety of fresh fruits and juices available on the polish market as determined by heavy metal residues. Pol. J. Environ. Stud. 2005, 16, 877-881.

10. Zhang, J.; Yang, R.D.; Li, Y.C.C.; Peng, Y.S.; Wen, X.F.; Ni, X.R. Distribution, accumulation, and potential risks of heavy metals in soil and tea leaves from geologically different plantations. Ecotoxicol. Environ. Saf. 2020, 195, 110475. [CrossRef]

11. Yaylalı-Abanuz, G.; Tüysüz, N. Heavy metal contamination of soils and tea plants in the eastern Black Sea region, NE Turkey. Environ. Earth Sci. 2009, 59, 131-144. [CrossRef]

12. Wen, B.; Li, L.; Duan, Y.; Zhang, Y.Y.; Shen, J.Z.; Xia, M.; Zhu, X.J. Zn, Ni, Mn, Cr, Pb and Cu in soil-tea ecosystem: The concentrations, spatial relationship and potential control. Chemosphere 2018, 204, 92-100. [CrossRef] [PubMed]

13. Pourret, O.; Lange, B.; Bonhoure, J.; Colinet, G.; Decree, S.; Mahy, G.; Seleck, M.; Shutcha, M.; Faucon, M.P. Assessment of soil metal distribution and environmental impact of mining in Katanga (Democratic Republic of Congo). Appl. Geochem. 2016, 64, 43-55. [CrossRef]

14. Ettler, V. Soil contamination near non-ferrous metal smelters: A review. Appl. Geochem. 2016, 64, 56-74. [CrossRef]

15. Wang, J.; Su, J.W.; Li, Z.G.; Liu, B.X.; Cheng, G.H.; Jiang, Y.H.; Li, Y.C.; Zhou, Y.C.; Zhou, S.Q.; Yuan, W.Y. Source apportionment of heavy metal and their health risks in soil-dustfall-plant system nearby a typical non-ferrous metal mining area of Tongling, Eastern China. Environ. Pollut. 2019, 254, 113089. [CrossRef] [PubMed]

16. Qu, S.; Wu, W.; Nel, W.; Ji, J. The behavior of metals/metalloids during natural weather: A systematic study of mono-lithological watersheds in the upper pearl river basin, China. Sci. Total Environ. 2020, 708, 134572. [CrossRef]

17. Bui, A.T.K.; Nguyen, H.T.H.; Nguyen, M.N.; Tran, T.H.T.; Vu, T.V.; Nguyen, C.H.; Reynolds, H.L. Accumulation and potential health risks of cadmium, lead and arsenic in vegetables grown near mining sites in Northern Vietnam. Environ. Monit. Assess. 2016, 188, 525. [CrossRef]

18. Song, B.; Zhang, Y.X.; Pang, R.; Yang, Z.J.; Bin, J.; Zhou, Z.Y.; Chen, T.B. Analysis of characteristics and sources of heavy metals in farmland soils in the Xijiang river draning of Guangxi. Environ. Sci. 2018, 39, 4317-4326.

19. Sun, Y.; Zhou, Q.; Xie, X.; Liu, R. Spatial, source, and risk assessment of heavy metal contamination of urban soils in typical regions of Shenyang, China. J. Hazard. Mater. 2010, 174, 455-462. [CrossRef]

20. Li, Z.; Ma, Z.; Van der Kuijp, T.J.; Yuan, Z.; Huang, L. A review of soil heavy metal pollution from mines in China: Pollution and health risk assessment. Sci. Total. Environ. 2014, 468-469, 843-853. [CrossRef]

21. Zhang, X.; Yang, H.; Cui, Z. Evaluation and analysis of soil migration and distribution characteristics of heavy metals in iron tailings. J. Clean. Prod. 2018, 172, 475-480. [CrossRef]

22. Wang, Y.J.; Liu, C.; Zhou, D.M.; Chen, H.M. A new approach for evaluating soil heavy metal impact: A comprehensive index combined soil environmental quality and agricultural products. J. Agro-Environ. Sci. 2016, 35, 1225-1232.

23. Wei, F.S.; Chen, J.S.; Wu, Y.Y.; Zheng, C.J. Background Value of Soil Environment in China. Environ. Sci. 1991, $12,12-19$.

24. Sun, J.; Hu, G.; Liu, K.; Yu, R.; Lu, Q.; Zhang, Y. Potential exposure to metals and health risks of metal intake from Tieguanyin tea garden soils and tea leaves. Chemosphere 2019, 246, 125638. [CrossRef]

25. Bi, C.J.; Zhou, Y.; Chen, Z.L.; Jia, J.P.; Bao, X.Y. Heavy metals and lead isotopes in soils, road dust and leafy vegetables and health risks via vegetable consumption in the industrial areas of Shanghai, China. Sci. Total Environ. 2018, 619, 1349-1357. [CrossRef]

26. Wang, F.; Shang, R.Y.; Chen, Y.Z.; Lin, D.L.; Zang, C.R.; Chen, C.S.; Yu, W.Q. Concentrations and health risk assessment of heavy metals in tea garden soil and tea-leaf from a mine county in central Fujian province. China Environ. Sci. 2018, 38, 1064-1072. [CrossRef]

27. Cao, H.B.; Qiao, L.; Zhang, H.; Chen, J.J. Exposure and risk assessment for aluminium and heavy metals in Puer tea. Sci. Total. Environ. 2010, 408, 2777-2784. [CrossRef] [PubMed]

28. Jones, J.B., Jr. Laboratory Guide for Conducting Soil Tests and Plant Analysis; CRC Press: Boca Raton, DC, USA, 1975. 
29. Li, X.H.; Gao, Y.; Zhao, W.F.; Liu, Z.J. Distribution characteristics of selenium in cultivated soil and its influencing factors in Qingtongxia city of Ningxia. J. Agric. Resour. Environ. 2018, 35, 422-429.

30. Chen, X.; Xia, X.; Zhao, Y.; Zhang, P. Heavy metal concentrations in roadside soils and correlation with urban traffic in Beijing, China. J. Hazard. Mater. 2010, 181, 640-646. [CrossRef]

31. Chary, N.S.; Kamala, C.T.; Raj, D.S. Assessing risk of heavy metals from consuming food grown on sewage irrigated soils and food chain transfer. Ecotoxicol. Environ. Saf. 2008, 69, 513-524. [CrossRef] [PubMed]

32. Sipter, E.; Rozsa, E.; Gruiz, K.; Tatrai, E.; Morvai, V. Site-specific risk assessment in contaminated vegetable gardens. Chemosphere 2008, 71, 1301-1307. [CrossRef]

33. De Oliverira, L.M.; Das, S.; da Silva, E.B.; Gao, P.; Gress, J.; Liu, Y.G.; Ma, L.Q. Metal concentrations in traditional and herbal teas and their potential risks to human health. Sci. Total Environ. 2018, 633, 649-657. [CrossRef]

34. Chang, C.Y.; Yu, H.Y.; Chen, J.J.; Li, F.B.; Zhang, H.H.; Liu, C.P. Accumulation of heavy metals in leaf vegetables from agricultural soils and associated potential health risks in the Pearl River Delta, South China. Environ. Monit. Assess. 2014, 186, 1547-1560. [CrossRef] [PubMed]

35. RoyChowdhury, A.; Datta, R.; Sarkar, D. Heavy metal pollution and remediation. In Green Chemistry; Elsevier: Amsterdam, The Netherlands, 2018; pp. 359-373. [CrossRef]

36. Sofuoglu, S.C.; Kavcar, P. An exposure and risk assessment for fluoride and trace metals in black tea. J. Hazard. Mater. 2008, 158, 392. [CrossRef] [PubMed]

37. Fatemi, H.; Zaghdoud, C.; Nortes, P.A.; Carvajal, M.; Martinez-Ballesta, M.D.C. Differential aquaporin response to distinct effects of two $\mathrm{Zn}$ concentrations after foliar application in Pak Choi (Brassica Rapa L.) plants. Agronomy 2020, 10, 450. [CrossRef] 